\title{
Media Convergence Meets Deconvergence
}

\author{
Corinna Peil and Sergio Sparviero
}

\section{Media Convergence as a Concept}

It is now more than thirty years since Ithiel de Sola Pool keenly observed a "convergence of modes" (Pool, 1983, p. 23), by which he referred to the increased connectivity between media and the erosion of formerly fixed boundaries. Ever since then, especially with the emergence and wide diffusion of the internet and online technologies, media convergence has been considered an overarching transition process and one of the major implications of digitization. As such, it has become a buzzword and a key issue in academic texts, policy documents and industrial papers (Diehl \& Karmasin, 2013; Dwyer, 2010; Fagerjord \& Storsul, 2007; Jenkins, 2006; Jensen, 2010; Jin, 2013; Lugmayr \& Dal Zotto, 2016a, b).

The term convergence indicates a movement directed towards, or terminating in, the same point, a "coming together of things that were previously separate" (Meikle \& Young, 2011, p. 2). In media and communications, where it has maintained unbroken popularity until today, it is used to describe a wide range of different developments and

We acknowledge the financial support of the Open Access Publication Fund of the University of Salzburg for the article processing charge.

\section{Peil $(\bowtie) \cdot$ S. Sparviero}

University of Salzburg, Salzburg, Austria

e-mail: corinna.peil@sbg.ac.at

(C) The Author(s) 2017

S. Sparviero et al. (eds.), Media Convergence and Deconvergence, Global Transformations in Media and Communication Research - A Palgrave and IAMCR Series, DOI 10.1007/978-3-319-51289-1_1 
transformations at the technological, industrial, cultural, social, spatial and political level (for example, Jenkins, 2006; Latzer, 2013; Miller, 2011; see also Balbi, Chap. 2 in this volume). An agreement concerning the existence of a media convergence at the level of technology stands out as the common denominator of different approaches. Although there have been forms of convergence in the pre-digitization era (see Balbi), contemporary appearances of a technological convergence have in common their being deeply rooted in the process of digitization. With the rise of a common digital standard, digitization has not only facilitated the recording, storage and transmission of data, but also enabled, for the first time, the decoupling of technologies and their respective media services: Digital media formats-be they voice, sound, text or film-were no longer restricted to one device only and, at the same time, almost all media devices were able to represent a plurality of different media formats and services. "This is the core of what is meant by technological convergence: all forms of media being increasingly stored and transferred on the same format and therefore becoming completely interchangeable" (Miller, 2011, p. 73).

Without adhering to a technological-deterministic view on media change, it seems safe to assume that, in the course of digitization, technological convergence has become a reality in today's media and communication landscape. Previously separate media technologies have indeed come closer together and lost their distinctive features; they are able to represent the same cultural forms and they provide similar functions and scopes of application. As all other forms of media convergence are linked to it, technological convergence can thus be considered an underlying feature of media convergence and a prerequisite for the emergence and development of other manifestations of convergence.

Taking technological convergence as a starting point, media convergence covers a set of different change processes at the macro, meso and micro level (Peil \& Mikos, 2017). At the macro level, it can be located in the context of a series of socio-cultural and economic transformations commonly described with keywords such as commercialization, globalization, deregulation and market liberalization. More specifically, the convergence of media and communications markets indicates the opportunities that became available to information and communication technologies (ICTs), media, and telecommunication corporations to expand their activities by redesigning their value chains and becoming multimedia companies. As a result of this process former telephone and cable providers, television stations, and hardware and software providers 
offer nowadays a variety of services ranging from the delivery of content to communications and connectivity, often bundled in packages. The resulting emergence of large multinational corporations has not only advanced a cross-media concentration process, but also imposed permanent changes on market structures and dynamics in the media sector which have been the subject of numerous convergence studies (Meikle \& Young, 2011, pp. 39-41; Miller, 2011, pp. 77-79). At the meso level, media convergence mainly concerns the alteration of media texts as well as their production and distribution. Content, genres and formats have merged in multiple ways and they are distributed over a variety of platforms and channels. As it is widely known, much work in this vein has been done by Henry Jenkins (2006) who elaborated in great depths on transmedia storytelling, the expansion of media texts and the participatory behavior of the media users in convergence cultures. At the micro level, attention is shifted to the users' activities in converging media environments (Peil \& Mikos, 2017). The latter are characterized by an extended ensemble of functional identical media technologies of which each affords a plethora of different applications, products and services. Convergent uses of media then refer to ways of access, to individual media biographies and interests and to related media repertoires (Hasebrink \& Domeyer, 2012; Kim, 2016; Stark, 2014), or, in short, to "media life," as Mark Deuze (2012) has described the extensive pervasion and increased invisibility of media in today's everyday life and its consequences for the users.

All these processes, which are included under the generic concept of media convergence, are evolving dynamically and with close relation to each other. In a certain way, they all predict a movement towards the dissolution of former fixed boundaries and a unification of discrete elements merging into some greater whole. The emergence of the particular and somehow defined vision of media convergence delineated above can be explained with the concept of "social imaginary," which defines the existence of widely shared understandings that have achieved general legitimacy (Mansell, 2012, p. 6), and which are produced, accepted and then taken for granted as "people seek some consistency in their experience of the 'reality' of their lives in a world of rapidly changing technologies and cultural and social norms" (Carpentier, 2011 cited in Mansell, 2012, p. 31). Therefore, here we claim that there is a widely shared understanding of the imperative nature of media convergence, which has taken a particular pathway associated with assumptions such as efficiency, synergy, 
simplification, information abundancy, participation, availability and multimodality. The elements of reality of this vision are multimedia companies exploiting the combined transmission of images, texts and sounds to offer better and cheaper products and services that facilitate the existence of active and participating users. As these images have achieved general legitimacy, they render media convergence a powerful concept, serving, among others, to influence the political agenda or to legitimize and justify policy decisions.

Nonetheless, these privileged meanings of media convergence, which emphasize the inevitability of the once adopted direction, are increasingly challenged. Media convergence is not about a newly achieved status quo (Jenkins, 2006, p. 16); rather, it relates to the idea of a process, a continuous change characterized by several parallel running developments and not terminating in a designated endpoint. Therefore, a variety of imaginaries exist. Critical viewpoints, for example, stress that media convergence has been used as a buzzword for outlining the impact of digitization while oversimplifying the complexity of media and technological change and neglecting the possibilities of modifying or turning around paths that have once been taken (Fagerjord \& Storsul, 2007; Storsul \& Stuedahl, 2007; Silverstone, 1995; see also Balbi, Chap. 2 in this volume).

Alternative views on transformation processes in today's mediatized societies are essential for a balanced view on media innovations and their advancement. Competing visions of media convergence include some recent ideas of a divergence process complementing and going hand in hand with media convergence (Fagerjord \& Stuehdahl, 2007; Lugmayr \& Dal Zotto, 2016c). According to this perspective, it is not the integration of media technologies, markets, uses and content but their disintegration, multiplication and increased complexity that are believed to be central features of recent developments. In order to grasp these often underexplored tendencies we suggest comprehending current transformations in media and communication as interplay of media convergence and deconvergence.

Deconvergence is a term originally coined by Jin $(2011,2013)$ to describe the breaking apart of media and communications companies through spin-offs, split-offs and demergers. It defines a trend that is a reaction to, and departs from, the convergence of media and communication markets, yet it is not divergence because it also unfolds in parallel to the former. In fact, as detailed below, in reaction to the digitization of 
media and communications, many companies in these sectors have followed either the strategy of expanding their capital and market opportunities, or the strategy of refocusing their operations around core activities, or both of these strategies at different points in time. Here, the term deconvergence is applied more broadly to different facets of the still dominant media convergence narrative to emphasize the interaction of converging and diverging movements in the media and communication sector. Taking into account processes of diversification and fragmentation as well as unresolved ambiguities that accompany media convergence or are a part of it, deconvergence also stands for the refusal to recognize the ongoing changes as linear, connected processes leading to predictable solutions. The perspective on deconvergence embraced in this book can help shed light on the ambivalent nature of media convergence and the simultaneity of competing forces such as coalescence and drifting apart, or linearity and discontinuity. Its purpose is to provide alternative viewpoints, which are often overlooked in the dominant readings of the concept. While these sites of tension constitute a general focus of this book, two of them, which are the user's perspective and the convergence of markets, are analyzed more carefully in the following sections. They demonstrate the contradictory nature of technological change and illustrate the ways its consequences for society are met.

\section{Media Convergence and Deconvergence from THE User's PERSPECTIVE}

One distinct area of media convergence discourse concerns the media users as well as their scope of actions and their behavior in convergent media environments. To begin with, there is not even a consensus as to what is meant by convergent media use. Empirical research in this vein shares a common interest in the people's media activities within environments that are less and less characterized by standalone media and their respective contexts of reception. It takes into consideration the ubiquitous and time-independent availability of media technologies that have similar or identical range of applications. The media repertoire approach by Hasebrink and Domeyer (2012), for example (see Hasebrink and Hölig, Chap. 6 in this volume, for further explications), describes the specific combination of media and content. Media repertoires refer to relatively stable, transmedia usage patterns that are perceived as the 
outcome of numerous media contacts resulting from concrete selection decisions. The polymedia concept introduced by Madianou and Miller (2012, p. 125) supposes the existence of media-saturated environments in which media technologies gain significance in relation to each other. Against this background, it focuses on the meaning-generating user practices that determine the single media's role within the media ensemble. Herkman (2012), with his concept of "intermediality," emphasizes historical continuities and contextual differences between media while Terje Rasmussen (2014) sees the media increasingly personalized and integrated into everyday life leading to a "networked lifeworld." The "mediatized world" approach (Hepp \& Krotz, 2014) also refers to a transmedia understanding of today's media environments, as it centers on the situations of media communication in the context of new technological possibilities. Taking into account the capacity of almost all media to provide similar content, communication modes and gratifications, the concept of "communicative figurations" (Hepp \& Hasebrink, 2013) looks at patterns of communication processes that exist over a variety of different media. The point of departure of all these newer, user-oriented approaches to media convergence is the decoupling of device and services, which render ineffective conclusions on usage based on the selection of media technology. Rather, the whole media ensemble, as well as the media's overlaps, is considered in order to comprehend how the discrete devices are used, combined and put in relation to each other.

For the purpose of describing the interplay of convergence and deconvergence from the user's perspective and to shed light on processes that so far have often been overlooked, three different dimensions of media usage have been identified where these antagonisms show in a particular way: (1) the proliferation of devices and media-related practices; $(2)$ the transmedia flow of content and the dissolution of distinctive usage scenarios; (3) the interconnection of media and the management of domestic infrastructures.

\section{The Proliferation of Devices and of Media Related Practices}

An early and central idea of media convergence touching the usage dimension has been the imagination of the "supermedium" (Jenkins, 2001; Herkman, 2012, p. 11) or the "Über-Box" (Fagerjord, 2002)— the emergence of an all-in-one device as single point of media contact 
where all media uses come together (see also van Dijk, 2012). This supermedium has in fact become a reality: Now, even the smallest media technology enables access to a great variety of functionalities and applications which were previously linked to standalone devices only. Highly personalized and portable online media like the smartphone integrate telecommunications, content and information technology, and thus represent in an almost paradigmatic manner one of the original notions of technological convergence. Yet this transformation of media into all-purpose devices is far from replacing the numerous technologies and boxes available in the home and offering a single solution for all the mediated activities of the users. In fact, almost every device has kept its unique place in the media ensemble. And since media have not only expanded their scope, but also specialized in terms of size, look and performance, households are now engaging with more devices than ever before. Described by Jenkins (2006, p. 14) as the "black box fallacy," the number and diversity of technologies has significantly increased in the last few years. And, equally, so have the standards, formats and practices of the users. Part of this convergence process is that the media have indeed moved closer together, as they are linked in manifold ways to one another. However, involving a high degree of disorder and complexity, the outcome of this development is not at all a streamlining of the media landscape. Rather than owning and making use of one personal all-round medium, users nowadays have to deal with an extremely sophisticated media environment and a multiplicity of media technologies, each of which comes with a specific focus or core competence and a broad range of functionalities. Traits of deconvergence thus appear in different forms of media access, in personalized media interests, in individualized media repertoires and in disparate media biographies.

The strong rise of media technologies, which is characteristic of convergent media environments, can be easily explained on the basis of the German long-term study Massenkommunikation (mass communication). In the response options of a question concerning the media equipment in the home, it listed only two electronic devices in the year 1970, but more than ten times as much in 2010 (van Eimeren \& Ridder, 2011, p. 3). Several of these devices enable internet access and thus facilitate the use of various applications that are provided by other media as well. Ultimately, after 2010 even more devices including tablet computers have contributed to the increased variety of multipurpose technologies 
available to the average household (Engel \& Breunig, 2015, p. 311). The users are thus able to make use of a certain media technology based on individual interests and demands. For any imaginable request they can select a specific device and assign a particular task to it. At the same time, the practices of media use have multiplied and diversified, too. Before digitization, one medium was usually related to only one form of activity (for example the radio was related to the practice of listening). Today, the above-mentioned study lists fifteen general online activities (for example, online banking, information seeking, forum discussions and so on) alone for the internet and seven activities linked to specific applications, like instant messaging or the involvement in photo communities (Frees \& Koch, 2015, p. 372). In addition, more than twenty activities are allocated to just one single online application, such as the use of online communities (for example, watching videos, uploading photos, posting and so on) (Busemann \& Gscheidle, 2012, p. 383). This variety of media-related activities exemplifies a fundamental shift of media communication which refers to a growing disparity rather than to a process of merging.

\section{The Transmedia Flow of Content and the Dissolution of Distinctive Usage Scenarios}

The interplay of media convergence and deconvergence becomes also apparent in the appropriation of media texts. On the one hand, media content, genres and modalities have grown together, most notably on the internet where written text, audiovisual content and interactive elements are regularly combined. On the other hand, the multiplication of distribution channels and the cost-effective production of digital content have led to the emergence of numerous platforms and to the differentiation of formats. As a consequence, the users have more options than ever to select the content they like while specialized interests can be met more easily by the producers. The convergence of media texts is thus likely to come along with greater individualization, fragmentation and deconvergence on the side of the users (Peil \& Mikos, 2017).

One strategy to deal with the increasingly complex and disordered flow of content is the concept of transmedia storytelling (Jenkins, 2006), which has gained much attention in media and communications. It refers to a new form of narration that creates a textual universe and an overall media experience around a specific narrative. Jenkins himself (2006, p. 19) 
speaks of the "art of world making" where different media are organized around a starting point, such as a movie or a TV series, in order to let the narrative expand onto diverse platforms and to maintain a continuous audience flow. Transmedia stories have to be functioning both within a single medium and as a narrative puzzle piece within a transmedia cosmos, comprising classic media as well as computer or mobile games and merchandising products (Peil \& Schwaab, 2014, p. 342; Peil \& Mikos, 2017). They are considered highly participative, driven top-down by the producers and also bottom-up by the users, who can decide how deep they want to immerse themselves in a given story. While the migration of texts across different media is constitutive of convergent media environments, the relocation of usage practices onto different devices and platforms indicates tendencies of deconvergence. In the shifting reception of television from the home TV set to the small display of the smartphone, Max Dawson (2007, p. 233), for example, has detected an "unbundling" of media objects: Larger program packages like an episode of a TV series or a news show are shaped into smaller, more easily consumed segments which are able to promote a falling apart of media experiences and a fragmentation of media usage into diminishing units of signification. By emphasizing the coexistence of separate media, second screens similarly refer to disintegration and a "crisis of convergence," as Stauff (2015, p. 127) explains: "'Second screen' therefore points at a not only simultaneous, but also interrelated and supplementary use of different screens, thereby undermining the clear distinction between separate media." Fleeting forms of media consumption and shorter periods of attention as well as parallel, overlapping uses of different media are thus likely to characterize media use in convergent media environments. In contrast, with the emergence of additional distribution channels like DVD boxes and streaming services, new forms of concentrated and time-consuming media reception have arisen, too, for instance, in the form of binge watching (Mikos, 2016) or "media marathoning" (Perks, 2015).

The described processes are ambiguous, and they are not fully captured by the notion of convergent media use. In "Convergence Culture", Jenkins (2006) refers to an intensified experience of media texts that are enhanced and improved through transmedia storytelling. The stories are too broad and complex for being told in one medium only. The activities of the users who engage in the text are perceived as richer and more comprehensive compared with past forms of media reception (Schwaab, 
2013). This association of an advanced condition or product is also part of the dominant social imaginary of media convergence. But rather than coming together or matching a harmonized textual universe, media usage is marked by overlaps of content, meaning and context (D'heer \& Courtois, 2016; Stauff, 2015; Vukanovic, 2016). The convergence of media texts thus corresponds with different forms of deconvergence, as illustrated in the increased complexity of usage situations. These are reflected in opposing tendencies, such as elusive and extensive forms of media reception, and in nonlinear and multidimensional consumption modes resulting from the ubiquitous availability of media texts and their independence from former technological restrictions.

\section{The Interconnection of Media and the Management of Domestic Infrastructures ${ }^{I}$}

A seamless interconnection of different media and their smooth interplay is part of the dominant social imaginary of media convergence, since convergence is expected "to allow user experiences to move fluidly through multiple content and devices" (Tavares \& Schofield, 2016, p. 246). While at the hardware level home networks need to be set up and maintained in order to establish the domestic infrastructures and manage the interrelations of convergent media technologies, cloud services are supposed to integrate media at the software level. In fact, cloud services seem to represent everything that convergence stands for: They integrate data, applications and personalized content, regardless of type or format, and make them available to users wherever they are and whenever they need them, thus supporting multi-device and cross-platform uses of media. In many respects, however, the idea of the unhindered interplay of media devices and the ubiquitous accessibility of content are inclined to conceal the disruptions and deconvergences that are involved in these processes.

First of all, unlimited interoperability and connection is not necessarily supported by the device manufacturers and service providers. Often, lock-in systems force users to receive content, services and applications from one brand only as switching to another brand goes with higher costs and inconveniences. "In digital cross-media culture, the specific affordances of each device or platform only unfold through interconnection with others; seamless connection, however, is guaranteed only 
by the 'walled garden' (the market power and proprietary technical standards) of one brand strongly constraining interoperability" (Stauff, 2015 , p. 132). As a matter of fact, infrastructures are shaped by the market's need to be profitable and to strengthen customer loyalty; they are not automatically geared towards convergence at the side of the users. Deconvergence comes into play when connections fail or there is a lack of compatibility between content producers and distribution platform, or between services and devices.

More important, the users themselves are often compromising the fluent interplay of media since the work of connecting devices and bringing content and services together within the personal media repertoire lies mainly in their hands. Even though software solutions suggest compensating for some of these exercises, their simplifying potential tends to be overvalued. "Far from serving to realize the putative end of labour in the home, new technologies often require significant work" (Kennedy, Nansen, Arnold, Wilken, \& Gibbs, 2015, p. 410). The labor of establishing media convergence includes diverse tasks such as setting up digital networks, storing, synchronizing and organizing data, and administering the media ensemble. In addition, with the increasing number of devices and shorter production cycles, regular and sometimes challenging updates, maintenance and coordination tasks become necessary. In light of the differentiation of almost each media device and given the permanent advancement of networked technologies these exercises can be demanding and frustrating (Montpetit, 2016). For a beneficial exploitation of convergent media environments, people need to have certain skills, they need to invest time, money and social capital in their media usage. This aspect of ability should not be underestimated as several studies point to the user's need for helpers and supporters who bring their technical expertise in order to connect media and make them work (Bakardjieva, 2005, p. 98; Courtois \& Verdegem, 2016; Peil \& Röser, 2014 , p. 241). In this sense, media convergence can be perceived as some kind of challenge or even burden for the users with the potential to tire them out or overstrain them. The dominant social imaginary of media convergence, represented in the idea of the harmonized and interconnected infrastructure, should therefore be complemented by the notion of labor that comes into play when dealing with manifestations of deconvergence at the level of structures and interfaces. 


\section{The Convergence and Deconvergence of Media and Communications Markets}

The diversity and complexity of the media environment just described is nowadays fostered by networks of specialized and interconnected companies. Nonetheless, as explained in this section, in reaction to the emergence of technical convergence, many large media and communication companies first attempted to engage in mergers and acquisitions (M\&As) in order to expand their capabilities and market shares of particular products. It is only in a later period that prioritizing the development of core competencies alongside the establishment of key partnerships became a more popular strategy to obtain these same goals. In this section, we review theoretical contributions and writings from business analysts and we attempt to explain these seemingly contradicting trends: market convergence and deconvergence.

\section{The Rationale for Market Convergence}

The main factors enabling the convergence of media and communications markets (in short, market convergence) were technological convergence and neoliberal globalization, defined as the process driven by policies designed and implemented to promote liberalization, deregulation, privatization and capital investment (Hesmondhalgh, 2013; Jin, 2013). In particular, the deregulation of the media and the telecommunication sectors, which is abundantly discussed in some of the chapters of this book, is the process that led to the removal of the existing barriers and the establishment of new comprehensive rules for competition in the emerging markets. These new rules, enacted in the US Telecommunications Act of 1996 and in the 1997 World Trade Organization Agreements, and supported by the 1997 EU Green Paper on Convergence, allowed corporations to own assets in different media and communication markets and to grow and expand their activities, not only domestically, but also internationally (Chon, Choi, Barnett, Danowski, \& Joo, 2003; Jin, 2013).

Moreover, the dominant social imaginary of market convergence has certainly been shaped by new giants, like Google, Facebook or, in former days, America Online (AOL), which quickly emerged as providers of new services based on the new technological opportunities. Notably, their efforts to innovate have not always been produced internally, within their own organization; on the contrary, their innovation strategy (still) 
supports integrating emerging new companies with their ideas and products, or, as it was the case for AOL (see Johnson, 2000), joining forces with an established player providing complementary skills and assets. However, the strategy of adapting to the new digital paradigm by integrating existing ventures into their value chains was pursued not only by a few new or large media and communications companies. The wave of M\&As that took place between the mid 1990s and the mid 2000s in the media, telecommunication and ICT sectors was indeed quite extensive and involved a variety of different organizations. While qualitative evidence is also provided by Jin and Rogers in their respective contributions to this collection, a quick illustration of the scope of this trend is provided elsewhere by Jin $(2013$, p. 112), who estimated the cumulative value of 103 mega-deals carried out between 1999 and 2008 to be 1326 billion dollars. $^{2}$

Many mergers and acquisitions between media and communication companies were presented to the authorities, the press and the shareholders, as attempts to generate economic value through the realization of synergies. This rather loose concept embraces a large variety of case scenarios that are contingent to the sector, the industry or specific companies. Nonetheless, from a more theoretical viewpoint, the realization of synergies through conglomeration generally includes the following five objectives (Flew, 2011; Ozanich \& Wirth, 2004): diversification (that is, spreading risks and opportunities across multiple industries and markets), the repurpose of media content over multiple platforms, the cross-promotion of media content across platforms, the creation of brands and the exploitation of subsidiary rights.

However, business innovation is a trial-and-error process driven by leaders that base their decisions not only on theoretical notions and on the information provided by (formal and less formal) research departments, but also on a generally accepted understanding of the current economic and business environments and of the technological trajectories of particular products and services. Notably, this happens in the case of M\&As between public companies because, prior to the realization of any benefits, the business leaders involved have to sell the merger or acquisition to investors, small or institutional, with ideas that the latter understand and are likely to embrace. Therefore, in order to comprehend the rationale for M\&As in this specific historical period, it is also useful to look into the specialized press, which refers to the opinions (mostly of them articulated simply through buzzwords) of analysts and of business leaders explaining their decisions. 
So, writing in 2001 about the Majors, which are the companies that dominate the distribution of blockbuster movies owned by the largest media and communication conglomerates, Harmon (2001) explained that combining content and distribution was viewed as a smart paradigm and the strategy improving the efficient exploitation of assets. Such was the case during the Golden Ages of the Hollywood studios (see also Sparviero, 2014). Following this smart paradigm were, among others, AOL-Time Warner, which aimed at expanding the distribution of its content over the internet, as well as Viacom and News Corporation focusing, respectively, on cable markets and satellite distribution. Also, given that governments became more lenient on limiting the cross-ownership of assets in the media and communication sectors, many companies pursued the strategy of expanding their assets through M\&As, simply because they were allowed and because many others did (Harmon, 2001). Finally, the large wave of M\&As in the media and communication sectors of the late 1990s to the mid 2000s can also be explained by the pursuit of the personal interests of public companies' key leaders and stakeholders. As explained by Gaughan (2011) in a critical text about current practices in corporate governance, many CEOs received important financial benefits from carrying out M\&As [Michael Cappellas, for example, received 14 million dollars in connection with the sales of Compaq to Hewlett-Packard, and, a few years later, 39 million dollars for the sale of MCI to Verizon (Gaughan, 2011, p. 490)]. Therefore, without necessarily doubting the good faith of the CEOs who earned important revenues for steering the process in favor of a merger or acquisition, one could nonetheless argue that these key stakeholders might also have been attracted by the amply available arguments explaining the benefits of integrating companies in the communication and media sectors because, finally, these helped them achieve personal goals.

\section{The Rationale for Market Deconvergence}

On the other hand, less attention is generally paid to the deconvergence of media and communications markets (or, in short, market deconvergence) - that is, the drastic slowdown of M\&A activities in the communication sector since 2002 , as well as the failure of $70 \%$ of the mega mergers carried out between 1998 and 2003 (as estimated in Jin, 2013), which also included the breaking apart of the most representative companies of the smart paradigm, namely Viacom-CBS (in 2006), 
AOL-Time Warner (in 2008), and News Corporation (in 2013), as well as the Financial Times (in 2015) (see Jin, Chap. 10 in this volume). ${ }^{3}$

Interestingly, this trend signals that, although M\&As in the media and communication sectors are still frequent, the pursuit of a deconvergence strategy is emerging as a new paradigm (Jin, 2013), regardless of the fact that the enabling conditions for market convergence are still present and that the goals of media and communications companies are still the same (that is, the maximization of their value by expanding operations and market shares). In this section and in line with the main theme of the book, we briefly concentrate on those consequences of technical convergence that are less explored and mostly excluded from the social imaginary which justifies market deconvergence.

First, split-offs and spin-offs in the media and communications sectors became more frequent in the new millennium in absolute numbers because mergers, which were particular frequent in the previous decade, often failed (Gaughan, 2011). The main reason evoked to generally explain the failed marriage between two companies is the presence of (organizational) cultural differences. An organization's culture can be understood also as collective habits or ways of thinking that can be altered only gradually (Langlois \& Robertson, 2002); these are indeed fundamental and believed to be a powerful force that determines priorities and decisions, influences behaviors and affects outcomes (Martin \& Frost, 1996; Schein, 1992, cited in Mierzjewska \& Hollifield, 2005). Therefore, a cultural clash in a company occurs when "two groups have different opinions about what really matters, what has to be measured, how to make better decisions, how to organize resources, how to supervise people, how to spread information and so on" (Ray, 2012, p. 40). These opinions, as the notion of organizational culture suggests, are embedded in the organization and they can evolve only slowly and arduously.

Hence, generally speaking, incumbent, traditional media companies, which have been established several decades before the digitization of media content and distribution, are based on different collective principles than the new media and IT ventures with which they merged. As a result, in many cases, distant organizational cultures have clearly been difficult to align and cultural clashes have certainly been the source of inefficiencies and obstacles to the realization of the promised synergies. Obviously, such a situation is particularly problematic for public companies that need to provide positive results in the short run. For example, as Ray (2012) explains, AOL, which was speedy and collaborative, 
focused and centralized, concentrated on the stock price and tight on spending, was far from being the perfect organizational match of Time Warner, a company described as slow and decentralized, diversified, focused on audience and costumer reach, and spendthrift. The lack of trust that was the consequence of these differences (Ray, 2012) hindered the development of an internet platform for the distribution of premium content produced by Time Warner while it was still merged with AOL.

Second, corporate focus, which has been a managerial buzzword since the 1980s and 1990s, is thought to be best served when the design of the organization, its control mechanism, the skills of the employees and the system of incentives are in line with the business of a company (Kirchmaier, 2001). Clearly, this alignment is simpler to achieve in smaller companies than in larger ones. Therefore, the volatile financial markets in the first decade of the new millennium brought in new perspectives and investors started to (re-)appreciate corporate focus and those companies that were prioritizing it before expanding in size. Thus, spin-offs were welcomed and seen as potentially value-creating when perceived as dispositions of assets outside of the core business (see Veld \& Veld-Merkoulova, 2009).

Moreover, market deconvergence can also be interpreted in more abstract terms as a particular trend that belongs to, and is the consequence of, the social and technical changes associated with the diffusion of digital technologies. This viewpoint presented here stems from the literature of innovation studies concerning the dynamics of technoeconomic paradigms (for example, Freeman \& Louçã, 2001) or great surges of development (for example, Perez, 2010). Techno-economic paradigms are long-term cycles of capitalist societies and are driven by the emergence of new pervasive technologies, but also by innovation and organizational principles, which are introduced mostly by the industries that design the new pervasive technologies and by changes to the socioinstitutional framework (see Perez, 2010).

The organizational principle of "the bigger the better" was applied successfully by the large manufacturer leading the previous techno-economic paradigm: the oil and the automobile industries, for example. The leading companies within these industries tend to be large, centrally and hierarchically managed and efficient in achieving economies of scope and scale in order to mass-produce standardized goods. Therefore, this principle is understandably part of the organizational culture of many established corporations, including the incumbent media organizations that 
emerged and/or developed between 1900 and the 1970s. However, to the contrary, the new industries that provided the technologies that digitized the economy are more likely to be organized as modular networks of interdependent activities, given that these organizational settings better suit the realization of a mass-customized production, the realization of economies of scope, increased specialization and the creation of niche markets (Perez, 2010), which are all factors providing companies with a competitive advantage.

There are many examples of goods and services that have emerged and diffused very quickly during the current techno-economic paradigm, that are indeed examples of innovations produced by modular networks. These include the personal computer, which merged audio, text and graphics by combining parts made by different companies (Campbell-Kelly \& Aspray, 2004). Also, the digital distribution of music is an example of media convergence by the adoption of a modular network, as traditional media content is delivered to end-users through a value chain composed of interdependent activities: for example, musician, label, digital music provider, internet provider (see Rogers \& Sparviero, 2011). According to Sturgeon (2002), modular production networks yield greater economic performance than other models, especially in the context of volatile demand, rapid technological change, and increasingly extensive and elaborate production geographies. Therefore, under these conditions, market deconvergence has created new performing companies that, through de-merger, spin-offs or split-offs, have opened up their value chains in order to integrate the products and innovations from a variety of stakeholders instead of focusing on realizing synergies with the activity of companies owned or controlled by the same corporation.

\section{Aims ANd SCOPE OF THE BoOK}

This book is to a large extent the main outcome of the conference "Deconstructing Media Convergence" that was held in Salzburg in November 2013. This 2-day meeting brought together scholars, who are regularly engaged in different sections of relevant international associations of communication: primarily the International Association for Media and Communication Research (IAMCR), then the European Communication Research and Education Association (ECREA) and others. This created a milieu of scholars coming from different research traditions and different disciplines including political economy, history and 
audience as well as communication policy and technology. Salzburg was the place where the authors had a chance to exchange ideas and reflect on the existence of critical viewpoints on the topic of media convergence in their respective fields of expertise. Based on these efforts, this edited collection gives alternative ideas of media convergence more visibility and a greater emphasis. By doing so, it explicitly takes a critical perspective, highlights the existence of opposing trends and explanations for these trends, and consequently distinguishes itself from existing collections and edited books on the same topic (for example, Diehl \& Karmasin, 2013; Grant \& Wilkinson, 2009; Jin, 2011, 2013; Lugmayr \& Dal Zotto, 2016a, b; Meikle \& Young, 2011; Nienstedt, Russ-Mohl, \& Wilczek, 2013).

This book is structured in four main parts. Part I consists of two chapters by the editors of this book which are meant to introduce into the field. While this chapter by Corinna Peil and Sergio Sparviero sheds light on the interplay of different social imaginaries of (de)convergence, Gabriele Balbi provides a critical history of the concept and its related meanings in different phases of its adoption. Part II of the book is dedicated to the options, practices and realities of the users in convergent media environments. As described above, the users have always been a major point of reference for dominant imaginaries of media convergence, depicting them either as overactive prosumers effortlessly navigating through their sophisticated media ensembles or as unknown entities indistinctly accessing convergent media devices with blurring modes of reception and usage. In this sense, taking into consideration traces of convergence, as well as deconvergence in the use of media, is complicated by the discrepancies regarding what is actually considered converging at the side of the users. Thus in Part II each of the contributions discusses the users' actions in relation to a specific complement of media consumption, be it technological affordances (Thimm), content and its distribution (Barra and Scaglioni), social and situational contexts (Müller and Röser), or audience research (Hasebrink and Hölig). What these chapters have in common is not only their critical assessment of the status quo, but also their reconsideration of what is often taken for granted when it comes to media convergence from the perspective of the users. Being committed to exploring the complex processes of change, they share an interest in revealing the ambiguities and inconsistencies that are involved in the user's practices, especially as they are not necessarily reproducing the transformations in other dimensions of media convergence. 
The non-linear and sometimes disruptive appropriation of convergent media technologies is clearly demonstrated by Kathrin F. Müller and Jutta Röser in their contribution about the media's interplay and domestic communication cultures in Germany. Based on their longitudinal, ethnographic study about the mediatization of the home, they show that the investigated households are far from replacing all "classic media" with online-capable convergent technologies. Rather, the situations and communicative settings of media consumption have proven to have a strong influence on media usage patterns in that they foster the use of already approved media. In most cases, convergent media use is something which is practiced in addition to established media routines while changes in the overall media setting have evolved only gradually. Luca Barra and Massimo Scaglioni provide a similar argument with regard to their research on the Italian television scenario. Considering media convergence both at the supply and at the user's side in their comprehensive study design, they come to the conclusion that audience practices are subject to constant changes and repeatedly shift between phases of deeper and more superficial convergence depending on technological innovations and program offers as well as on sociocultural and economic factors. Coming from a media logic perspective, Caja Thimm emphasizes the technological properties which come into play when using convergent media in today's digital environments. With the concept of media grammar she explains how technologies predefine a specific framework for the communicative practices of the users that are shaped by the possibilities and constraints provided. Along with the change of technological infrastructure, there has been an alteration of the public sphere by the formation of so called "polymedia media-publics" or "mini-publics." In this context, media convergence seems no longer an apt concept to describe current phenomena as it does not take into account the emergence of complex technological systems and related usage cultures. Uwe Hasebrink and Sascha Hölig then critically discuss how to overcome current challenges in audience research in order to grasp what media convergence actually means from the perspective of the users and how it translates into practices. They propose the two concepts of media repertoires and communication modes to explain how the media are put in relation to each other and how users, despite the complex and convergent media environments they inhabit, skillfully differentiate between a variety of distinctive media-related practices. 
In Part III, the three chapters show some of the ambiguities of media convergence in the production and distribution of content. Thanks to digitization, previously distinguished media content (audio, video, text) is translated into binary language so that it can be produced, distributed and consumed more easily, rapidly and with minor costs. According to the mainstream research, looking rather positively at the potential of technological convergence, media texts can be centrally produced in order to be played out across different channels, platforms and networks, that is once they are developed, they can be readapted and flow through different media. On a closer look, however, the production and distribution of media content is far from being a standardized and linear process and, again, it is characterized by differentiations and disruptions. Another dominant media convergence narrative concerns new production dynamics of media texts: Digital and convergent media have often been interpreted enthusiastically, mainly because of their assumed ability to free audiences from the control of the one-to-many mass and analog media. Digital content can be easily generated, personalized, manipulated, actively changed and distributed through different channels: this brings consumers and producers closer (even linguistically with the concept of "prosumers") in the convergent media environment. Nevertheless, when researched, all these processes show some ambiguities.

Mark Eisenegger, Mario Schranz and Angelo Gisler focus their attention on the newsroom, comparing online and offline media content in Switzerland. They come to at least three counter-intuitive conclusions about media convergence: first, it has caused the concentration of media producers against the narrative of diversification in the digital world; second, at least in Switzerland, it seems to have led to a loss of quality, especially compared with traditional printed press reports; finally, convergence is based on an unprofitable strategy because of the audience unwillingness to pay for online content. This latter outcome goes against the narrative that media convergence would naturally produce new opportunities for revenues and would be profitable in general. Lothar Mikos' chapter deals with television and analyzes two media convergence strategies (transmedia storytelling and mega-narration) as the main answers given by TV producers and channels to the increasing market and audience fragmentation. Again, Mikos provides a critical perspective, claiming that these production strategies foster further audience fragmentation because of the personal and nearly infinite possibility of choice. Consequently, narratives indicating that transmedia storytelling 
and mega-narration are effective strategies to control audiences and to make a product easily successful need to be revised.

Matthew Allen's chapter is a reprint and a partial update of a paper published in the journal First Monday in 2008. Allen claims that, instead of seeing the internet and specifically the web as the main "product" of media convergence, some of the key elements of Web 2.0 are so incompatible with traditional mass media as to act against the convergence between old and new media technologies. This can be illustrated by four examples: Web 2.0 sites and services are more like a computer program than a TV program and they cannot be combined; advertising appeal of websites is again different from traditional media because it is not about consuming media products (and advertising with them) but about doing things; third, according to Allen, in the Web 2.0 users are primary producers of content instead of being consumers as in a traditional media environment; finally, Web 2.0 has often been seen as a vehicle for democratization, while traditional broadcasting has been often seen as an expression of established hegemony. In sum, Web 2.0 does not converge with traditional media in terms of production, but rather creates a different model.

Part IV of the book focuses on the changes brought about by digitization in the organization of the media industries, in the reconfiguration of media markets, and in the influence of policy and regulations. In these particular areas, the most popular images of media convergence predict the expansion of existing corporations and the emergence of new giants, a process that is enabled and sustained by a process of deregulation that removes the separation between communications, connectivity and media services. Notably, deregulation is assumed to be leading to free(r) markets. However, the alternative pictures that emerge from the critical analyses presented in this part of book show that media corporations have rediscovered the practice of enhancing the core competencies of their subdivisions, by engaging in split-offs, spin-offs and joint ventures in order to improve their value. In addition, these alternative pictures show that, although the process of deregulation has certainly affected the reconfiguration of media and communications markets, deregulated does not mean unregulated or less regulated: new tensions between stakeholders have emerged and new regulations have been established. Essentially this means that in the longer run, when the process of deregulation that in Western economies peaked in the late 1990s will be in a more mature stage, there will be different rules, but not necessarily fewer rules. 
This part opens with the chapter by Dal Yong Jin, where he describes the coupling of convergence and deconvergence of media and communications markets, as well as the recent emergence of the latter as the main business paradigm. Interestingly, while he provides specific examples and the rationale for deconvergence, he also explains that nowadays M\&As in this sectors tend to be horizontal, rather than vertical, stressing that the business strategy of investing in core competencies is nowadays at least as popular as attempting to create synergies between complementary activities. Next is the chapter by Jim Rogers, which focuses on the music industry and explains how the digitization of the distribution of media content have enabled the creation of new revenue streams, which, from the viewpoint of the whole industry, compensate for the loss in the sale of records. Nonetheless, while new players have emerged and value chains have been redrawn, the music business is still dominated largely by a handful of corporations.

The tensions between service providers and the struggle for the emergence of new regulations are the focus of the chapter by Hilde Van den Bulck, who supports her findings using three different case studies of media restructuring and policymaking in Flanders, Belgium. On the other hand, Paul Murschetz responds to the challenge of understanding the new complex media environment by exploring the applicability of the contingency theory of organizations, which he illustrates with the example of the evolution of the digital TV broadcasting environment in Germany. Finally, the chapter by Christopher Ali and that by Fei Jiang, Kuo Huang and Yanran Sun elaborate on the process of policymaking in two very different socioeconomic environments: the USA and China. Nonetheless, interestingly, parallel dynamics unfold: the coming together of different technologies and the potential for their exploitation is not matched by the coming together, or the full collaboration, of existing regulatory authorities, which are forced to review their own role in policymaking. In the USA, the user's prospects of accessing locally relevant content through cheaper and better connections are partly undermined by conflicts between federal, state and local authorities. Similarly, in China, besides the determination of the central government to enhance connectivity and to favor the establishment of new services, conflicts between two powerful departments, one governing telecommunications and the other governing the media, have so far hindered this plan. 


\section{Notes}

1. The expression domestic infrastructures refers to the networked media settings and technologies at home and thus slightly contrasts with the technical dimensions and material artefacts of national and transnational infrastructures that are discussed in, among others, Parks and Starosielski (2015).

2. A mega-deal is defined here as a merger or acquisition that is in the top 100 of the year in which it occurred and in terms of the new company's value (Jin, 2013).

3. The failure of an M\&A is defined as the split-off of the companies prior the M\&A, and/or the spin-off of some activities from the merged company, and/or the bankruptcy of the merged company.

\section{REFERENCES}

Bakardjieva, M. (2005). Internet society. The internet in everyday life. London: Sage. Busemann, K., \& Gscheidle, C. (2012). Web 2.0: Habitualisierung der Social Communitys: Ergebnisse der ARD/ZDF-Onlinestudie 2012. Media Perspektiven, 7-8, 380-390.

Campbell-Kelly, M., \& Aspray, W. (2004). Computer: A history of the information machine (2nd ed.). Boulder, Colorado, USA: Westview Press.

Carpentier, N. (2011). Media and participation: A site of ideological-democratic struggle. Intellect Ltd. Retrieved from http://www.oapen.org/ search?identifier $=606390$.

Chon, B. S., Choi, J. H., Barnett, G. A., Danowski, J. A., \& Joo, S.-H. (2003). A structural analysis of media convergence: Cross-industry mergers and acquisitions in the information industries. Journal of Media Economics, 16(3), 141157. doi:10.1207/S15327736ME1603_1.

Courtois, C., \& Verdegem, P. (2016). With a little help from my friends: An analysis of the role of social support in digital inequalities. New Media \& Society, 18(8), 1508-1527.

Dawson, M. (2007). Little players, big shows. Format, narration, and style on television's new smaller screens. Convergence: The International Journal of Research into New Media Technologies, 13(3), 231-250.

Deuze, M. (2012). Media life. Cambridge, UK, Malden, MA: Polity Press.

D'heer, E., \& Courtois, C. (2016). The changing dynamics of television consumption in the multimedia living room. Convergence: The International Journal of Research into New Media Technologies, 22(1), 3-17.

Diehl, S., \& Karmasin, M. (Eds.). (2013). Media and convergence management. Berlin, Heidelberg: Springer. Retrieved from http://www.springer.com/ business+\%26+management/media+management/book/978-3-642-36162-3. 
Dwyer, T. (2010). Media convergence. Maidenhead, New York: McGraw Hill/ Open University Press.

Engel, B., \& Breunig, C. (2015). Massenkommunikation 2015: Mediennutzung im Intermediavergleich: Ergebnisse der ARD/ZDF-Langzeitstudie. Media Perspektiven, 7-8, 310-322.

Fagerjord, A. (2002). Reading-View(s)ing the Über-Box: A Critical View on a Popular Prediction. In M. Eskelinen \& R. Koskimaa (Eds.), Cybertext Yearbook 2001 (pp. 99-110). Jyväskylä: Publications of the Research Centre for Contemporary Culture.

Fagerjord, A., \& Storsul, T. (2007). Questioning convergence. In T. Storsul \& D. Stuedahl (Eds.), Ambivalence towards convergence: Digitalization and media change (pp. 19-31). Göteborg: Nordicom.

Flew, T. (2011). Media as creative industries. In D. Winseck \& D. Y. Jin (Eds.), Political economies of the media: The transformation of the global media (pp. 84-100). USA: Bloomsbury.

Frees, B., \& Koch, W. (2015). Internetnutzung: Frequenz und Vielfalt nehmen in allen Altersgruppen zu: Ergebnisse der ARD/ZDF-Onlinestudie 2015. Media Perspektiven, 9, 366-377.

Freeman, C., \& F. Louça. (2001). As Time Goes by: From the Industrial Revolutions to the Information Revolution. Oxford, New York: Oxford University Press.

Gaughan, P. A. (2011). Mergers, acquisitions, and corporate restructurings (5th ed.). Hoboken, NJ: Wiley.

Grant, A. E., \& Wilkinson, J. (2009). Understanding media convergence: The state of the field. Oxford, New York: Oxford University Press.

Harmon, A. (2001, December 15). Hollywood's new force: The strategy; '01 media model: Content and distribution go together. The New York Times. Retrieved from http://www.nytimes.com/2001/12/15/business/hollywood-s-new-force-strategy-01-media-model-content-distribution-gotogether.html.

Hasebrink, U., \& Domeyer, H. (2012). Media repertoires as patterns of behaviour and as meaningful practices: A multimethod approach to media use in converging media environments. Participations. Journal of Audience and Reception Studies, 9(2), 757-779.

Hepp, A., \& Hasebrink, U. (2013). Human interaction and communicative figurations. The Transformation of Mediatized Cultures and Societies. Communicative Figurations, Working Paper No. 2, 1-22.

Hepp, A., \& Krotz, F. (Eds.). (2014). Mediatized worlds: Culture and society in a media age. Basingstoke: Palgrave Macmillan.

Herkman, J. (2012). Introduction: Intermediality as a theory and methodology. In J. Herkman, T. Hujanen, \& P. Oinonen (Eds.), Intermediality and media change. Tampere: Tampere University Press. 
Hesmondhalgh, D. (2013). The cultural industries (3rd ed.). London: Sage.

Jenkins, H. (2001). Convergence? I diverge: For all the talk about "convergence," multiple media will never coalesce into one supermedium. MIT Technology Review, 01 June 2001.

Jenkins, H. (2006). Convergence culture: Where old and new media collide. New York: New York University Press.

Jensen, K. B. (2010). Media convergence: The three degrees of network, mass, and interpersonal communication. London, New York: Routledge.

Jin, D. Y. (2011). De-convergence and the deconsolidation in the global media industries: The rise and fall of (some) media conglomerates. In D. Winseck \& D. Y. Jin (Eds.), Political economies of the media: The transformation of the global media (pp. 167-182). London, UK: Bloomsbury.

Jin, D. Y. (2013). De-convergence of global media industries. New York: Routledge.

Johnson, T. (2000, January 10). That's AOL folks. Retrieved 25 May 2011, from http://money.cnn.com/2000/01/10/deals/aol_warner/.

Kennedy, J., Nansen, B., Arnold, M., Wilken, R. \& Gibbs, M. (2015). Digital housekeepers and domestic expertise in the networked home. Convergence: The International Journal of Research into New Media Technologies, 21(4), 408-422.

Kim, S. J. (2016). A repertoire approach to cross-platform media use behavior. New Media \& Society, 18(3), 353-372.

Kirchmaier, T. (2001). Corporate demergers: Or is divorce more attractive than marriage. CentrePiece, (Spring), 14-17.

Langlois, R. N., \& Robertson, P. L. (2002). Firms, markets and economic change: A dynamic theory of business institutions. London: Routledge.

Latzer, M. (2013). Convergence, co-evolution and complexity in European communications policy: Working Paper of the Media Change \& Innovation Division <mediachange.ch $>$. Zurich, Switzerland.

Lugmayr, A., \& Dal Zotto, C. (Eds.). (2016a). Media convergence handbook Vol. 1: Journalism, Broadcasting, and Social Media Aspects of Convergence. Berlin, Heidelberg: Springer.

Lugmayr, A., \& Dal Zotto, C. (Eds.). (2016b). Media convergence handbook Vol. 2: Firms and user perspectives. Berlin: Springer.

Lugmayr, A., \& Dal Zotto, C. (2016c). Media convergence is NOT king: The triadic phenomenon of media "convergence-divergence-coexistence" is king. In A. Lugmayr, \& C. Dal Zotto (Eds.), Media convergence handbook - Vol. 2: Firms and user perspectives (pp. 429-55). Berlin, Heidelberg: Springer.

Madianou, M., \& Miller, D. (2012). Polymedia: Towards a new theory of digital media in interpersonal communication. International Journal of Cultural Studies, 16(2), 169-187. 
Mansell, R. (2012). Imagining the Internet: Communication, innovation, and governance. Oxford: Oxford University Press.

Martin, J., \& Frost, P. (1996). The organizational culturewar games: A struggle for intellectual dominance. In S. R. Clegg, C. Hardy, \& W. R. Nord (Eds.), Handbook of organization studies (pp. 599-621). London: Sage.

Meikle, G., \& Young, S. (2011). Media convergence: Networked digital media in everyday life. Basingstoke: Palgrave Macmillan.

Mierzjewska, B. I., \& Hollifield, C. A. (2005). Theoretical approaches in media management research. In A. B. Albarran, S. M. Chan-Olmsted, \& M. O. Wirth (Eds.), Handbook of media management and economics (1st ed., pp. 37-66). London: Routledge.

Mikos, L. (2016). Digital media platforms and the use of TV content: Binge watching and video-on-demand in Germany. Media and Communication, $4(3), 154-161$.

Miller, V. (2011). Understanding digital culture. London, Thousand Oaks: Sage. Montpetit, M.-J. (2016). The 2nd convergence: A technology viewpoint. In A. Lugmayr \& C. Dal Zotto (Eds.), Media convergence handbook - Vol. 1: Journalism, broadcasting, and social media aspects of convergence (pp. 29-57). Berlin, Heidelberg: Springer.

Nienstedt, H.-W., Russ-Mohl, S., \& Wilczek, B. (2013). Journalism and media convergence. Berlin: De Gruyter.

Ozanich, G. W., \& Wirth, M. (2004). Structure and change: A communications industry overview. In A. Alexander, J. Owers, R. A. Carveth, C. A. Hollifield, \& A. N. Greco (Eds.), Media economics. Theory and practice (pp. 69-84) Mahwah, NJ, London: Lawrence Erlbaum Associates.

Parks, L., \& Starosielski, N. (Eds.). (2015). Signal traffic. Critical studies of media infrastructures. Champaign: University of Illinois Press.

Peil, C., \& Mikos, L. (2017): Konvergierende Medienumgebungen. In L. Mikos \& C. Wegener (Eds.), Qualitative Medienforschung. Ein Handbuch. (pp. 209218). Konstanz: UVK.

Peil, C., \& Röser, J. (2014). The meaning of home in the context of digitization, mobilization and mediatization. In A. Hepp \& F. Krotz (Eds.), Mediatized worlds: Culture and society in a media age (pp. 233-249). Basingstoke: Palgrave Macmillan.

Peil, C., \& Schwaab, H. (2014). Hello-Kitty-Konsum als Kommunikationskultur. Zur Ver-alltäglichung und Vergegenständlichung eines cute characters. In M. Mae \& E. Scherer (Eds.), Nipponspiration. Japonismus und japanische Populärkultur im deutschsprachigen Raum (pp. 335-353). Wien, Köln, Weimar: Böhlau.

Perez, C. (2010). The Financial Crisis and the Future of Innovation: A View of Technical Change with the Aid ofHistory. The Other Canon Foundation and 
Tallinn University of Technology. Working Papers in TechnologyGovernance and Economic Dynamics, 1-42.

Perks, L. G. (2015). Media marathoning. Immersions in morality. Lanham: Lexington Books.

Pool, I. de S. (1983). Technologies of freedom. Cambridge, Mass, London: Belknap Press of Harvard University Press.

Rasmussen, T. (2014). Personal media and everyday life. A networked lifeworld. Basingstoke: Palgrave Macmillan.

Ray, S. (2012). Cultural dimension analysis of AOL-time Warner Merger. Journal of Applied Library and Information Science, 1(2), 39-41.

Rogers, J., \& Sparviero, S. (2011). Understanding innovation in communication industries through alternative economic theories: The case of the music industry. International Communication Gazette, 73, 610-629. doi:10.1177/1748048511417158.

Schein, E. H. (1992). Organizational culture and leadership (2nd ed., Vol. 356). New York: Wiley.

Schwaab, H. (2013). Transmedialität und Mediatisierung. Formen und Motive der Expansion serieller Welten und neuer Medienobjekte. Navigationen, $13(1), 85-103$.

Silverstone, R. (1995). Convergence is a dangerous word. Convergence, l(1), $11-13$.

Sparviero, S. (2014). The creative destruction of the United States' audio-visual media ecosystem. In P. Wikstrom \& R. DeFillippi (Eds.), International perspectives on business innovation and disruption in the creative industries: Film, video, photography (pp. 128-148). Cheltenham, UK: Edward Elgar Publishing Ltd.

Stark, B. (2014). Informationsverhalten im 21. Jahrhundert-eine repertoireorientierte Analyse veränderter Nutzungsmuster. In K. Kleinen von Königslöw \& K. Förster (Eds.), Medienkonvergenz und Medienkomplementarität aus Rezeptions- und Wirkungsperspektive (pp. 37-57). Baden-Baden: Nomos Verlag. Stauff, M. (2015). The second screen: Convergence as crisis. ZMK Zeitschrift für Medien- und Kulturforschung, 6(2), 123-144.

Storsul, T., \& Stuedahl, D. (Eds.). (2007). Ambivalence towards convergence: Digitalization and media change. Göteborg: Nordicom.

Sturgeon, T. J. (2002). Modular production networks: A new American model of industrial organization. Industrial and Corporate Change, 11(3), 451-496.

Tavares, T. A. \& Schofield, D. (2016). Interaction design for convergence medias and devices: A multisensory challenge. In A. Lugmayr \& C. Dal Zotto (Eds.), Media convergence handbook - Vol. 2: Firms and user perspectives (pp. 245-260). Berlin, Heidelberg: Springer. 
van Dijk, J. A. (2012). The network society. London: Sage.

van Eimeren, B., \& Ridder, C.-M. (2011). Trends in der Nutzung und Bewertung der Medien 1970 bis 2010: Ergebnisse der ARD/ZDFLangzeitstudie Massenkommunikation. Media Perspektiven, 1, 2-15.

Veld, C., \& Veld-Merkoulova, Y. V. (2009). Value creation through spin-offs: A review of the empirical evidence. International Journal of Management Reviews, 11(4), 407-420. doi:10.1111/j.1468-2370.2008.00243.x.

Vukanovic, Z. (2016). Converging Technologies and Diverging Market Trends of Internet/Web and Traditional Media. In A. Lugmayr \& C. Dal Zotto (Eds.), Media Convergence Handbook - Vol. 2. Firms and User Perspectives (pp. 69-93). Berlin, Heidelberg: Springer.

\section{Authors' Biography}

Corinna Peil is a Postdoctoral Researcher at the University of Salzburg's Department of Communication Studies, Center for Information and Communication Technologies \& Society (ICT\&S), Austria. Her research and teaching focus is on mobile communications, media (de)convergence, online publics, the use of media in everyday life contexts, and the mediatization of society.

Sergio Sparviero is an Assistant Professor at the Department of Communication Studies of the University of Salzburg, Austria. His main field of research and teaching are: media economics; media management; and media innovation. In particular, he published research on the developments of the news, film and music industries. He is also the coordinator of the Erasmus + Joint Master Program "Digital Communication Leadership" (DCLead).

Open Access This chapter is licensed under the terms of the Creative Commons Attribution 4.0 International License (http://creativecommons.org/licenses/ by $/ 4.0 /)$, which permits use, sharing, adaptation, distribution and reproduction in any medium or format, as long as you give appropriate credit to the original author(s) and the source, provide a link to the Creative Commons license and indicate if changes were made.

The images or other third party material in this chapter are included in the chapter's Creative Commons license, unless indicated otherwise in a credit line to the material. If material is not included in the chapter's Creative Commons license and your intended use is not permitted by statutory regulation or exceeds the permitted use, you will need to obtain permission directly from the copyright holder.

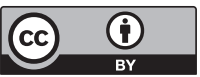

